\title{
Prior Exposure to Alcohol Has No Effect on Cocaine Self-Administration and Relapse in Rats: Evidence from a Rat Model that Does Not Support the Gateway Hypothesis
}

\author{
Ida Fredriksson 1,3, Sweta Adhikary², Pia Steensland ${ }^{3}$, Leandro F Vendruscolo ${ }^{4}$, Antonello Bonci ${ }^{1,5,6}$, \\ Yavin Shaham*,2 and Jennifer M Bossert ${ }^{2}$ \\ 'Cellular Neurobiology Branch, IRP-NIDA, NIH, Baltimore, MD, USA; ${ }^{2}$ Behavioral Neuroscience Branch, IRP-NIDA, NIH, Baltimore, \\ MD, USA; ${ }^{3}$ Centre for Psychiatry Research, Department of Clinical Neuroscience, Karolinska Institutet \& Stockholm Health Care Services, \\ Stockholm, Sweden; ${ }^{4}$ Integrative Neuroscience Research Branch, IRP-NIDA NIH, Baltimore, MD, USA; ${ }^{5}$ Solomon H. Snyder Neuroscience Institute, \\ Johns Hopkins University School of Medicine, Baltimore, MD, USA; 'Department of Psychiatry, Johns Hopkins University School of Medicine, \\ Baltimore, MD, USA
}

\begin{abstract}
The gateway hypothesis posits that initial exposure to legal drugs promotes subsequent addiction to illicit drugs. However, epidemiological studies are correlational and cannot rule out the alternative hypothesis of shared addiction vulnerability to legal and illegal drugs. We tested the gateway hypothesis using established rat alcohol exposure procedures and cocaine self-administration and reinstatement (relapse) procedures. We gave Wistar or alcohol-preferring (P) rats intermittent access to water or $20 \%$ alcohol in their homecage for 7 weeks (three 24-h sessions/week). We also exposed Wistar rats to air or intoxicating alcohol levels in vapor chambers for 14-h/day for 7 weeks. We then tested the groups of rats for acquisition of cocaine self-administration using ascending cocaine doses $(0.125,0.25,0.5,1.0 \mathrm{mg} / \mathrm{kg} /$ infusion) followed by a dose-response curve after acquisition of cocaine self-administration. We then extinguished lever pressing and tested the rats for reinstatement of drug seeking induced by cocaine-paired cues and cocaine priming $(0,2.5,5,10 \mathrm{mg} / \mathrm{kg}$, i.p.). Wistar rats consumed moderate amounts of alcohol $(4.6 \mathrm{~g} / \mathrm{kg} / 24 \mathrm{~h}), \mathrm{P}$ rats consumed higher amounts of alcohol $(7.6 \mathrm{~g} / \mathrm{kg} / 24 \mathrm{~h})$, and Wistar rats exposed to alcohol vapor had a mean blood alcohol concentration of $176.2 \mathrm{mg} / \mathrm{dl}$ during the last week of alcohol exposure. Alcohol pre-exposure had no effect on cocaine self-administration, extinction responding, and reinstatement of drug seeking. Pre-exposure to moderate, high, or intoxicating levels of alcohol had no effect on cocaine self-administration and relapse to cocaine seeking. Our data do not support the notion that alcohol is a gateway drug to cocaine.
\end{abstract}

Neuropsychopharmacology (2017) 42, I00I-101।; doi:I0.1038/npp.2016.209; published online 21 December 2016

\section{INTRODUCTION}

In a recent US survey of high school seniors, $84.4 \%$ of all cocaine users reported that they began alcohol drinking or cigarette smoking before they began to use cocaine (Johnston et al, 2014). These results are in agreement with those from other epidemiological studies showing that initial exposure to legal drugs is associated with subsequent use of illicit drugs (Kandel, 1975; Kandel et al, 1992; Kirby and Barry, 2012; Wagner and Anthony, 2002). These findings led to the formulation of the 'gateway' hypothesis that posits that initial exposure to legal drugs causes subsequent addiction to illicit drugs (Kandel et al, 1992). However, epidemiological studies are correlational and cannot rule out the alternative

*Correspondence: Dr Y Shaham, NIDA, IRP Behavioral Neuroscience Branch 25I Bayview Blvd, Suite 200, Baltimore, MD 21044, USA, Tel: + I 410 740-2723, Fax: + I 4I0 740-2727,

E-mail: yshaham@intra.nida.nih.gov

Received 30 June 2016; revised 2 September 2016; accepted 13 September 2016; accepted article preview online 21 September 2016 hypothesis of time-independent shared addiction vulnerability to legal and illegal drugs (Vanyukov et al, 2012). In addition, human studies cannot test experimentally the gateway hypothesis, because a definitive study will require random assignment of subjects to groups exposed or not exposed to the legal drug. The gateway hypothesis can be tested in animal models where pre-exposure to the legal drug is under experimenter control. In our study, we empirically tested whether there is a biological basis for the gateway hypothesis with established rat models using alcohol and cocaine as prototypical legal and illegal drugs, respectively. Although the legal status of some drugs (eg, marijuana) may change over time, it is unlikely that cocaine will become a legal drug in the foreseeable future in the United States and other countries.

Several previous studies examined whether prior alcohol exposure increases cocaine conditioned place preference (CPP). In four studies, adolescent mice (Mateos-Garcia et al, 2015; Molet et al, 2013) or rats (Hutchison and Riley, 2012), or adult rats (Hutchison and Riley, 2012) that were 
pre-exposed to alcohol showed increased cocaine CPP. In contrast, Le Pen et al (1998) reported that alcohol preexposure in adult rats decreased subsequent cocaine CPP in low but not high alcohol drinkers. However, the relevance of these studies to the gateway hypothesis is limited, because the drug CPP procedure is not a good model of human addiction, because drug exposure is very low and independent of the subject's behavior (Lu et al, 2003).

Two previous studies examined whether prior alcohol exposure increases cocaine self-administration in rats. Mierzejewski et al (2003) trained rats to self-administer alcohol in the sucrose-fading procedure and then divided them into low $v s$ high alcohol self-administration. They reported that the high-intake group self-administered more cocaine during the initiation phase. However, the results of this study are difficult to interpret in the context of the gateway hypothesis, because the authors did not include a control group of alcohol-naive rats that only selfadministered sucrose during training. In addition, the authors used a single cocaine dose. Thus, it is unknown whether increased drug intake reflects increased or decreased cocaine reward (Yokel, 1987).

More recently, Mateos-Garcia et al (2015) intermittently exposed adolescent male and female mice to alcohol (twicedaily, $2.5 \mathrm{~g} / \mathrm{kg}$, i.p) during adolescence and reported that this exposure modestly increased acquisition of cocaine selfadministration but not drug self-administration under a progressive ratio reinforcement schedule. A limitation of this study, in which the authors also reported that prior alcohol exposure increased cocaine CPP, is that group differences in acquisition of cocaine self-administration may be due to the non-specific effects of alcohol as a pharmacological stressor (Sarnyai et al, 2001). Indeed, exposure to alcohol doses lower than the one used by Mateos-Garcia et al are aversive to adolescent rats (Philpot et al, 2003). Thus, as stress exposure early in life can increase cocaine self-administration (Lu et al, 2003; Marinelli and Piazza, 2002; Piazza and Le Moal, 1998), an alternative interpretation of Mateos-Garcia et al results is that alcohol increased cocaine self-administration not because of its rewarding effects, but because it induced a chronic stress-like state during adolescence. In conclusion, several studies have tested the gateway hypothesis using CPP and cocaine self-administration procedures in rodents. However, because of methodological and conceptual considerations described above, we conclude that the data in these studies neither support nor refute this hypothesis.

Here, we tested the gateway hypothesis in three experiments in which we used outbred Wistar rats and alcoholpreferring (P) rats and exposed them to alcohol using established alcohol pre-exposure procedures (intermittent access for $20 \%$ alcohol or alcohol vapor) for an extended period time (7 weeks) (Roberts et al, 2000; Simms et al, 2008; Wise, 1973); we exposed the rats to alcohol during the late adolescence/early adulthood phase (Figure 1b) (McCutcheon and Marinelli, 2009; Spear, 2015). We then tested the rats for differences in acquisition of cocaine self-administration using an ascending dose-response procedure (Goeders and Guerin, 1994; Stewart et al, 1996) and cocaine dose-response curve after acquisition. Next, we tested whether alcohol preexposure increases resistance to extinction, an established measure of drug seeking (Shalev et al, 2002; Venniro et al, 2016), and reinstatement of cocaine seeking induced by
Table I Inactive Lever Presses During the Extinction and Reinstatement Tests (mean \pm SEM per $\mathrm{I}-2 \mathrm{~h}$ )

\begin{tabular}{lcccc}
\hline & $\begin{array}{c}\text { Extinction } \\
\text { no cue }\end{array}$ & $\begin{array}{c}\text { Cue } \\
\text { reinstatement }\end{array}$ & $\begin{array}{c}\text { Extinction } \\
\text { with cue }\end{array}$ & $\begin{array}{c}\text { Priming } \\
\text { reinstatement }\end{array}$ \\
\hline Exp. I & & & & \\
Water & $13.1 \pm 2.3$ & $12.7 \pm 2.7$ & $8.8 \pm 1.9$ & $2.7 \pm 1.0$ \\
Low & $8.9 \pm 1.8$ & $7.5 \pm 2.0$ & $7.4 \pm 1.5$ & $2.7 \pm 1.0$ \\
alcohol & & & & \\
High & $4.4 \pm 1.3$ & $5.8 \pm 1.3$ & $5.7 \pm 1.9$ & $1.5 \pm 0.6$ \\
alcohol & & & & \\
& & & & \\
Exp. 2 & & & & \\
Air & $8.1 \pm 2.3$ & $8.6 \pm 2.6$ & $6.1 \pm 1.1$ & $1.4 \pm 0.3$ \\
Vapor & $8.1 \pm 1.6$ & $7.8 \pm 2.0$ & $5.9 \pm 1.1$ & $0.9 \pm 0.3$ \\
& & & & \\
Exp. 3 & & & & \\
Water & $7.8 \pm 1.0$ & $10.3 \pm 2.6$ & $6.8 \pm 0.9$ & $2.9 \pm 0.7$ \\
Alcohol & $6.4 \pm 0.9$ & $6.2 \pm 1.2$ & $5.2 \pm 0.6$ & $3.6 \pm 0.7$ \\
\hline
\end{tabular}

discrete cocaine cues (Meil and See, 1996) and cocaine priming injections (de Wit and Stewart, 1981).

\section{MATERIALS AND METHODS}

\section{Overview of Experimental Procedures}

We gave Wistar (Exp. 1) or P rats (Exp. 3) intermittent access to water or $20 \%$ alcohol in their home cage for 7 weeks. We also exposed another group of Wistar rats (Exp. 2) to air or intermittent (14h/day) intoxicating levels of alcohol for 7 weeks. We then tested the rats in the different experiments in the following identical sequence of test phases (Figure 1): Acquisition of cocaine self-administration, dose-response curve following the acquisition phase, extinction responding without the discrete cue, cue-induced reinstatement, extinction responding with the discrete cue, and cocaine priminginduced reinstatement (Table 1). For a detailed description of the experimental methods and the specific experiments see Supplementary online Materials and Methods Section.

\section{RESULTS}

\section{Exp. 1. Wistar Rats: Prior Exposure to Intermittent Access to $20 \%$ Alcohol}

The timeline of Exp. 1 is provided in Figure 1a. Before testing the rats for acquisition of cocaine self-administration, extinction, and reinstatement of cocaine seeking, we gave the rats intermittent access to water $(n=12)$ or $20 \%$ alcohol $(n=24)$ in their home cage for 7 weeks. We then divided the alcohol-exposed rats to two groups based on median split for the last week of drinking: low alcohol intake (mean \pm SEM of $3.0 \pm 0.3 \mathrm{~g} / \mathrm{kg} / 24 \mathrm{~h}, n=12$ ) and high alcohol intake (mean \pm SEM of $5.8 \pm 0.5 \mathrm{~g} / \mathrm{kg} / 24 \mathrm{~h}, n=12$ ) (Figure 1c, Exp. 1).

We also correlated the data for the preference for alcohol over water with the data for alcohol intake based on $\mathrm{g} / \mathrm{kg}$ during the last week of drinking and these measures were 
a

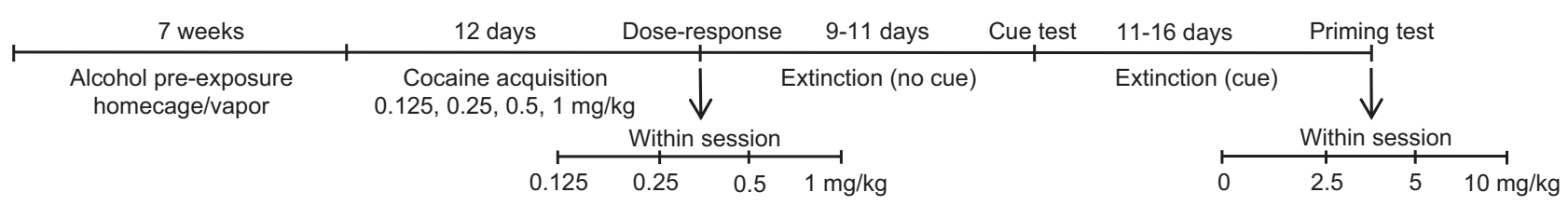

b
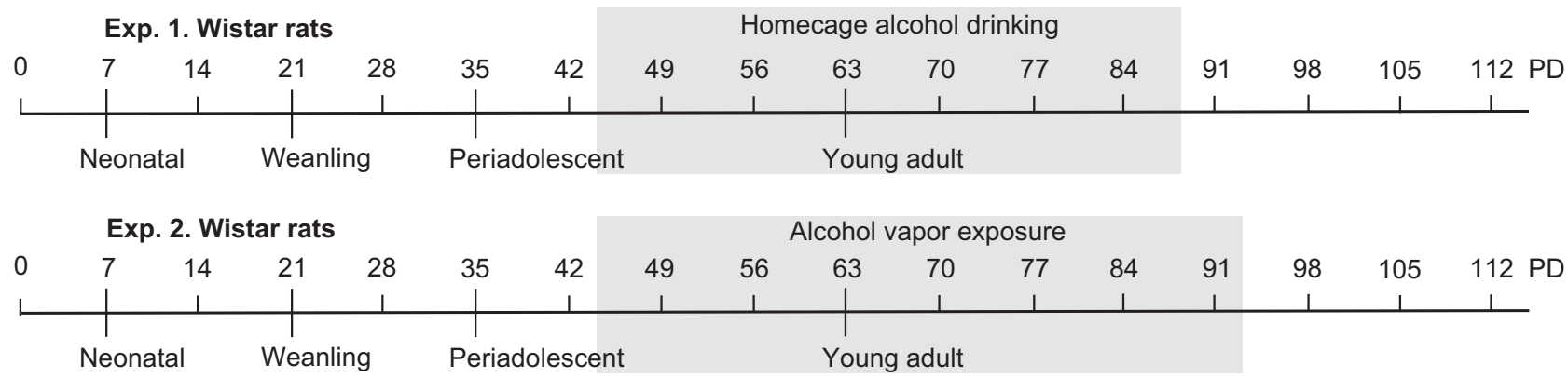

Exp. 3. $P$ rats

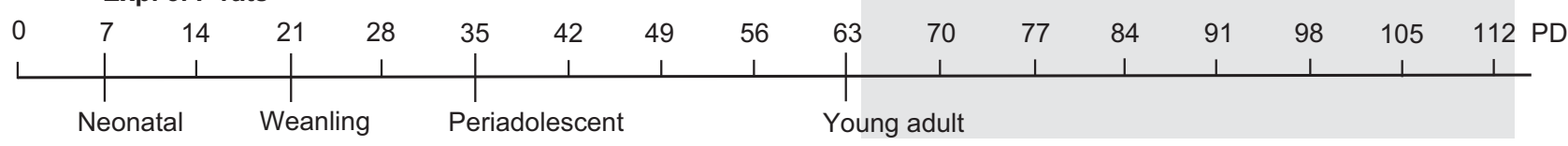

C

Alcohol intake and blood alcohol levels
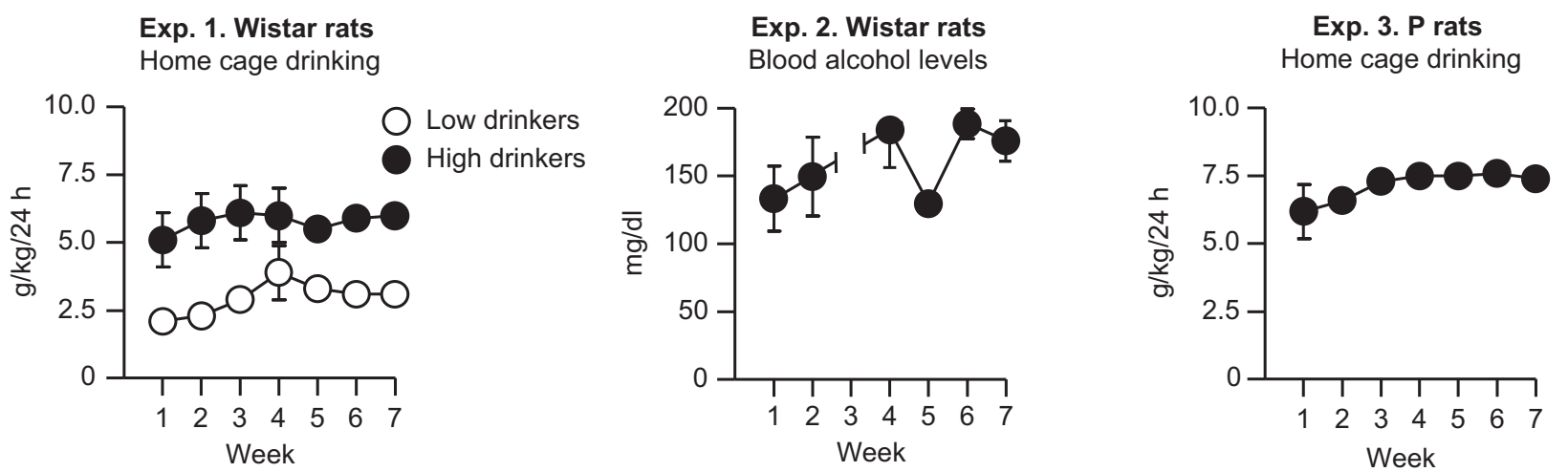

Figure I Experimental timeline, and age of onset of alcohol exposure, and alcohol pre-exposure. (a) Outline of the experimental procedures. (b) Age of onset of alcohol exposure in Exp. I-3; the chronological timeline is based on McCutcheon and Marinelli (2009). (c) Left panel: alcohol intake (g/kg) in Wistar rats (Exp. I; $n=12$ per group) during intermittent home-cage access to 20\% alcohol. Middle panel: blood alcohol levels (mg/dl) in Wistar rats (Exp. 2; $n=12$ ) during alcohol vapor exposure. Right panel: Alcohol intake $(\mathrm{g} / \mathrm{kg})$ in P-rats (Exp. 3; $n=15)$ during intermittent home-cage access to $20 \%$ alcohol. Data are presented as mean \pm SEM.

positively correlated (low alcohol intake: $r=0.84 p=0.001$; high alcohol intake: $r=0.55 p=0.07)$. Despite the lack of a significant correlation between alcohol intake and preference score in the high alcohol intake group, the lowest preference score in the high alcohol intake group was higher than the highest preference score in the low alcohol intake group. Overall, alcohol pre-exposure had no effect on the different measures of cocaine self-administration, extinction responding, and reinstatement of cocaine seeking. In addition, there were no correlations between mean alcohol intake $(\mathrm{g} / \mathrm{kg})$ and the different cocaine taking and seeking measures, except for a negative correlation in the high alcohol intake group for the $0.25 \mathrm{mg} / \mathrm{kg} /$ infusion dose during acquisition of cocaine selfadministration (Supplementary Table S1, Supplementary Information). Below we provide the statistical results for the different experimental phases.

Acquisition of cocaine self-administration and cocaine dose-response after acquisition

Acquisition (left panel). (Figure 2, Exp. 1) The analysis of the number of cocaine infusions included the between-subjects factor of Pre-exposure condition (water, 
Exp. 1. Wistar rats: home cage exposure

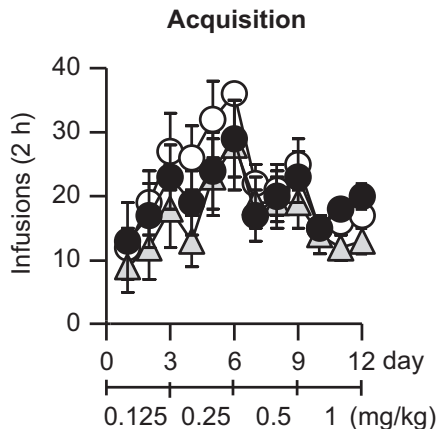

Dose-response after acquisition

Exp. 2. Wistar rats: alcohol vapor exposure
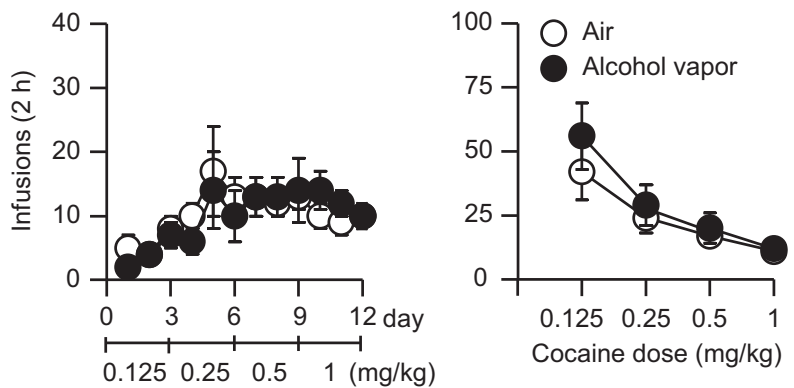

Exp. 3. P-rats: home cage exposure
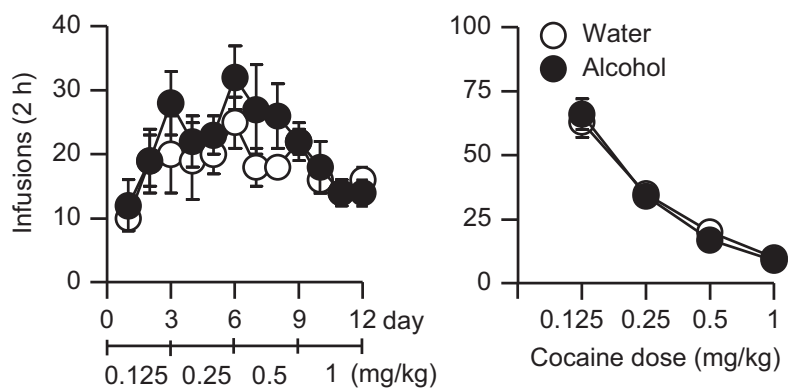

Figure 2 Acquisition of cocaine self-administration and dose-response after acquisition. Left panel: acquisition of cocaine self-administration with ascending doses of cocaine ( $3 \mathrm{~d}$ per dose) in Exp. I-3. Right panel: withinsession dose-response curve after acquisition of cocaine self-administration in Exp. 1-3. Data are mean \pm SEM of cocaine infusions per $2 \mathrm{~h}$. Exp. I: $n=10-12$ per group; Exp. 2: $n=8-1 \mid$ per group; Exp. 3: $n=12-14$ per group.

low alcohol intake, high alcohol intake) and the withinsubjects factors of Cocaine dose $(0.125,0.25,0.5,1.0 \mathrm{mg} / \mathrm{kg})$ and Training session (session 1, 2, and 3 for each dose). This analysis showed significant effects of Cocaine dose $\left(\mathrm{F}_{3,90}=8.8, p<0.01\right)$, Training session $\left(\mathrm{F}_{2,60}=36.4, p<0.01\right)$, and interaction between the two factors $\left(\mathrm{F}_{6,180}=4.5\right.$, $p<0.01)$. There were no significant effects of Pre-exposure condition or an interaction between this factor and the other factors ( $p$-values $>0.05)$.

Dose-response after acquisition (right panel). The analysis of number of cocaine infusions showed a significant effect of Cocaine dose $\left(\mathrm{F}_{3,87}=81.3, p<0.01\right)$ but no effects of Pre-exposure condition or an interaction between the two factors ( $p$-values $>0.05)$.
Exp. 1. Wistar rats: home cage exposure

Extinction without cue

Cue reinstatement
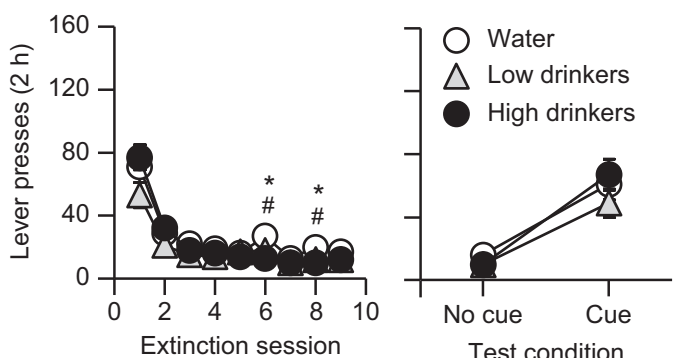

Exp. 2. Wistar rats: alcohol vapor exposure
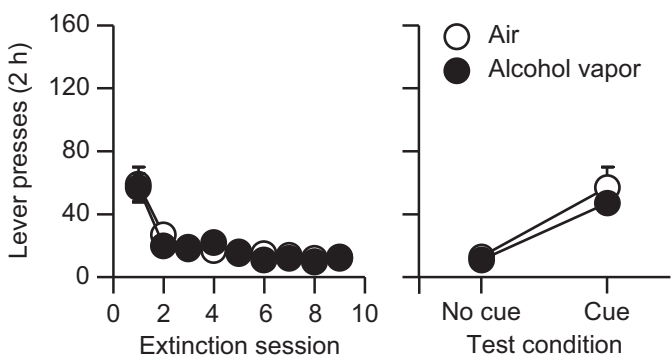

Exp. 3. P-rats: home cage exposure
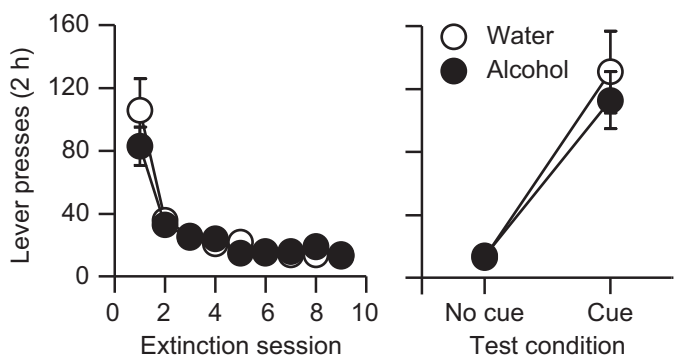

Figure 3 Extinction responding without cue and cue-induced reinstatement. Left panel: extinction responding without cue over nine extinction sessions in Exp. 1-3. Right panel: cue-induced reinstatement in Exp. I-3. During testing, lever presses led to contingent presentation of the light cue but not cocaine. The No cue data are the mean of the last three extinction sessions without the cue. Data are mean \pm SEM of active lever presses per 2 h. Exp. I: $n=10-1$ I per group; Exp. 2: $n=8-1$ I per group; Exp. 3: $n=12-14$ per group. \# a significant difference between water and low alcohol intake; * a significant difference between water and high alcohol intake (Exp. I), $p<0.05$

\section{Extinction without cue and cue-induced reinstatement}

Extinction without cue (left panel). (Figure 3, Exp. 1) The analysis of number of active lever presses, which included the between-subjects factor of Pre-exposure condition and the within-subjects factor of Extinction session (session 1-9), showed significant effects of Extinction session $\left(\mathrm{F}_{8,216}=22.1, p<0.01\right)$ and an interaction between Preexposure condition and Extinction session $\left(\mathrm{F}_{16,216}=2.5\right.$, $p=0.01$ ), but no significant effect of Pre-exposure condition $(p>0.05)$. The reason for the significant interaction is the somewhat lower responding of the low alcohol intake group in the two first extinction sessions.

Cue-induced reinstatement (right panel). The analysis of number of active lever presses showed a significant effect 
Exp. 1. Wistar rats: home cage exposure
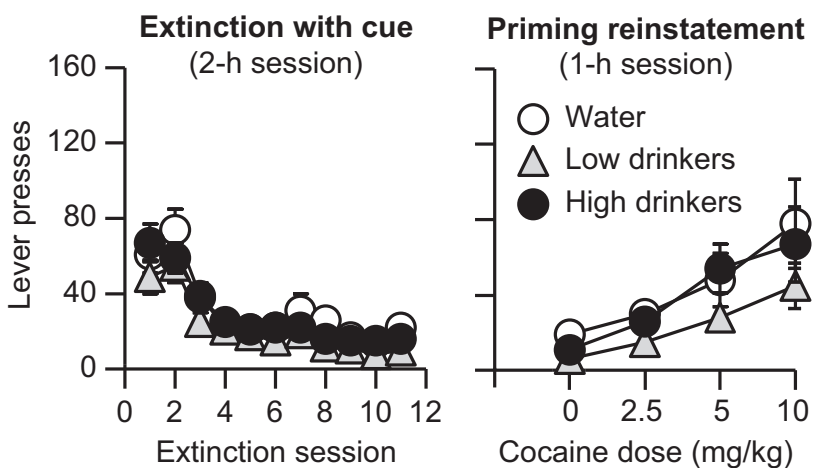

Exp. 2. Wistar rats: alcohol vapor exposure

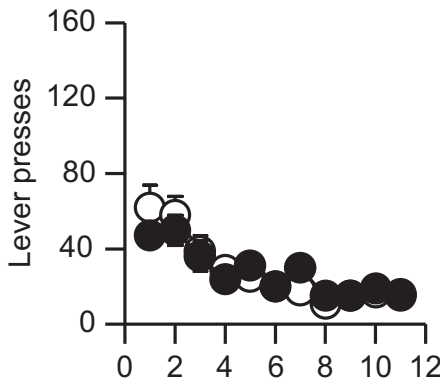

Extinction session

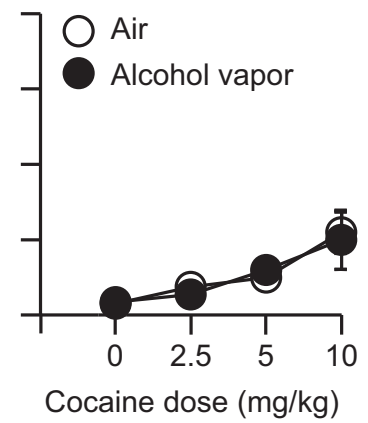

Exp. 3. P-rats: home cage exposure
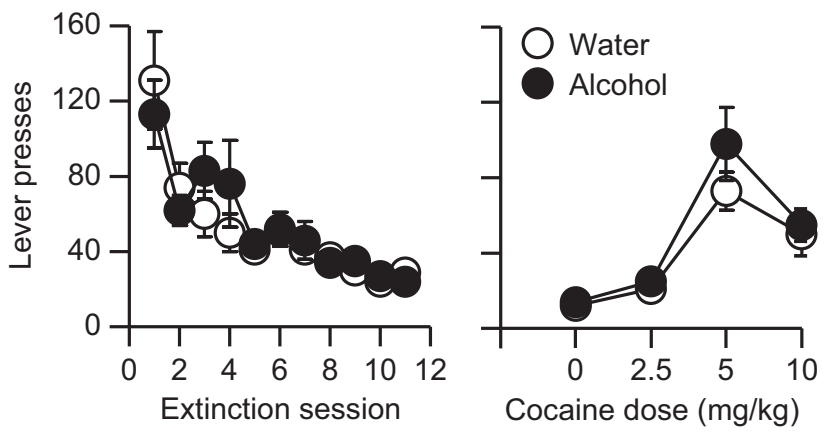

Figure 4 Extinction responding with cue and drug priming-induced reinstatement. Left panel: extinction responding with cue over I I extinction sessions in Exp. I-3. Right panel: priming-induced reinstatement of cocaine seeking $(0,2.5,5$, and $10 \mathrm{mg} / \mathrm{kg}$, IP) in Exp. I-3. During testing, lever presses led to contingent presentation of the light cue but not cocaine. Data are mean \pm SEM of active lever presses per $2 \mathrm{~h}$ for extinction sessions and per I $h$ for priming-induced reinstatement. Exp. I: $n=10-1 \mid$ per group; Exp. 2: $n=8-10$ per group; Exp. 3: $n=12-14$ per group.

of Cue condition $\left(\mathrm{F}_{1,27}=14.3, p<0.01\right)$ but no effects of Pre-exposure condition or an interaction between the two factors ( $p$-values $>0.05)$.

\section{Extinction with cue and priming-induced reinstatement}

Extinction with cue (left panel). (Figure 4, Exp. 1) The analysis of number of active lever presses showed significant effects of Extinction session (session 1-11) $\left(F_{10}, 270=8.9\right.$, $p<0.01$ ), but no effects of Pre-exposure condition or interaction between the two factors $(p>0.05)$.
Priming-induced reinstatement (right panel). The analysis of number of active lever presses showed significant effects of Cocaine priming dose $\left(\mathrm{F}_{3,81}=4.4, p<0.01\right)$ but no effects of Pre-exposure condition or an interaction between the two factors ( $p$-values $>0.05)$.

\section{Exp. 2. Wistar Rats: Prior Exposure to Alcohol Vapor Chambers}

The timeline of Exp. 2 is provided in Figure 1a. Before testing the rats for acquisition of cocaine self-administration, extinction, and reinstatement of cocaine seeking, we gave the rats intermittent access to air (control condition; $n=12$ ) or intoxicating levels of alcohol vapor $(162.2 \pm 10.6 \mathrm{mg} / \mathrm{dl}$; $n=12$ ) for 7 weeks (Figure 1c, Exp. 2). Overall, alcohol pre-exposure had no effect on the different measures of cocaine self-administration, extinction responding, and reinstatement of cocaine seeking.

Acquisition of cocaine self-administration and cocaine dose-response after acquisition

Acquisition (left panel). (Figure 2, Exp. 2) The analysis of the number of cocaine infusions included the betweensubjects factor of Pre-exposure condition (air, alcohol vapor), the within-subjects factors of Cocaine dose and Training session. This analysis showed significant effects of Cocaine dose $\left(\mathrm{F}_{3,51}=6.4, p<0.01\right)$, but no effects of Training session or an interaction between the two factors $(p$-values $>0.05)$. In addition, there were no significant effects of Pre-exposure condition or interactions between this factor and the other factors ( $p$-values $>0.05)$.

Dose-response after acquisition (right panel). The analysis of number of cocaine infusions showed a significant effect of Cocaine dose $\left(\mathrm{F}_{3,51}=20.2, p<0.01\right)$ but no effects of Pre-exposure condition or an interaction between the two factors ( $p$-values $>0.05)$.

Extinction without cue and cue-induced reinstatement

Extinction without cue (left panel). (Figure 3, Exp. 2) The analysis of number of active lever presses, which included the between-subjects factor of Pre-exposure condition and the within-subjects factor of Extinction session (session 1-9), showed a significant effect of Extinction session $\left(\mathrm{F}_{8,128}=4.6, p<0.01\right)$ but no effects of Pre-exposure condition or an interaction between the two factors ( $p$-values $>0.05)$.

Cue-induced reinstatement (right panel). The analysis of number of active lever presses showed a significant effect of Cue condition $\left(\mathrm{F}_{1,16}=9.4, p<0.01\right)$ but no effects of Pre-exposure condition or an interaction between the two factors $(p$-values $>0.05)$.

Extinction with cue and priming-induced reinstatement

Extinction with cue (left panel). (Figure 4, Exp. 2) The analysis of number of active lever presses showed a significant effect of Extinction session (session 1-11) $\left(\mathrm{F}_{10,150}=2.5, \quad p<0.01\right)$ but no effects of Pre-exposure condition or an interaction between the two factors $(p$-values $>0.05)$. 
Priming-induced reinstatement (right panel). The initial ANCOVA analysis (inactive lever as a covariate) of number of active lever presses showed no significant effects of Cocaine priming dose, Pre-exposure condition, or an interaction between the two factors ( $p$-values $>0.05$ ). However, a post hoc ANOVA of active lever presses (without the inactive lever responses as the covariate) showed a significant effect of Cocaine priming dose $\left(\mathrm{F}_{3,48}=11.1, p<0.01\right)$ but no significant effects of Pre-exposure condition or an interaction between the two factors ( $p$-values $>0.05)$. The reason for the differences between the ANCOVA with the inactive lever as the covariate and the ANOVA is not clear because the inactive lever presses were very low across the different conditions $(0-3.75$ presses per $1 \mathrm{~h})$. However, owing to the very low variability in inactive lever presses, the repeated measures ANOVA of inactive lever presses showed a significant effect of Cocaine priming dose $\left(\mathrm{F}_{3,48}=3.3\right.$, $p<0.05)$, but no significant effects of Pre-exposure condition or an interaction between the two factors ( $p$-values $>0.05$ )

\section{Exp. 3. Alcohol Preferring $P$ rats: Prior Exposure to Intermittent Access to $20 \%$ Alcohol}

The timeline of Exp. 3 is provided in Figure 1a. Before testing the rats for acquisition of cocaine self-administration, extinction, and reinstatement of cocaine seeking, we gave the rats intermittent access to water $(n=14)$ or $20 \%$ alcohol (mean \pm SEM of $7.2 \pm 0.2 \mathrm{mg} / \mathrm{kg} / 24 \mathrm{~h} ; n=15$ ) in their home cage for 7 weeks (Figure 1c, Exp. 3). Overall, alcohol preexposure had no effect on the different measures of cocaine self-administration, extinction responding, and reinstatement of cocaine seeking. In addition, there were no significant correlations between mean alcohol intake $(\mathrm{g} / \mathrm{kg})$ and the different cocaine measures of cocaine taking and seeking (Supplementary Table S1, Supplementary Information).

Acquisition of cocaine self-administration and cocaine dose-response after acquisition

Acquisition (left panel). (Figure 2, Exp. 3) The analysis of the number of cocaine infusions included the betweensubjects factor of Pre-exposure condition (water, alcohol), and the within-subjects factors of Cocaine dose and Training session. This analysis showed significant effects of Cocaine dose $\left(\mathrm{F}_{3,72}=4.7, p<0.01\right)$, Training session $\left(\mathrm{F}_{2,48}=10.6\right.$, $p<0.01)$, and an interaction between the two factors $\left(\mathrm{F}_{6,144}=2.8, p<0.05\right)$. There were no significant effects of Pre-exposure condition or interactions between this factor and the other factors ( $p$-values $>0.05)$.

Dose-response after acquisition (right panel). The analysis of number of cocaine infusions showed a significant effect of Cocaine dose $\left(\mathrm{F}_{3,72}=111.0, p<0.01\right)$ but no effects of Pre-exposure condition or an interaction between the two factors ( $p$-values $>0.05)$.

\section{Extinction without cue and cue-induced reinstatement}

Extinction without cue (left panel). (Figure 3, Exp. 3) The analysis of number of active lever presses, which included the between-subjects factor of Pre-exposure condition and the within-subjects factor of Extinction session

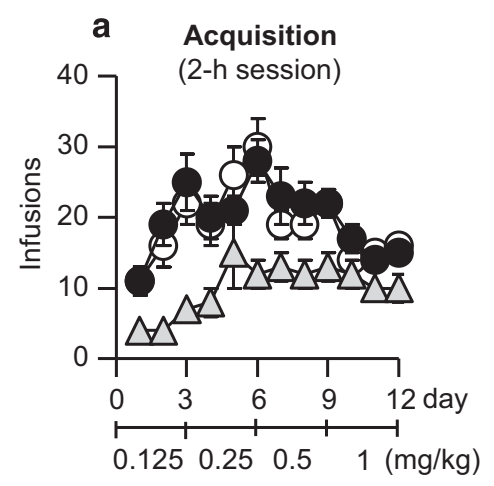

b Dose-response curve
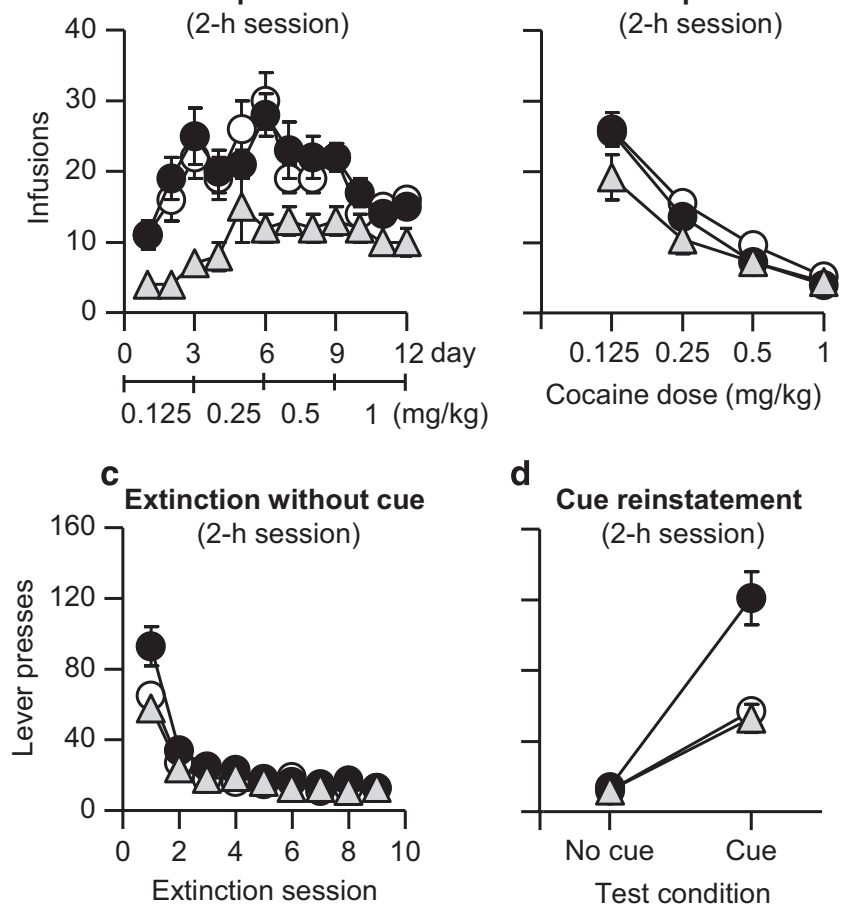

d

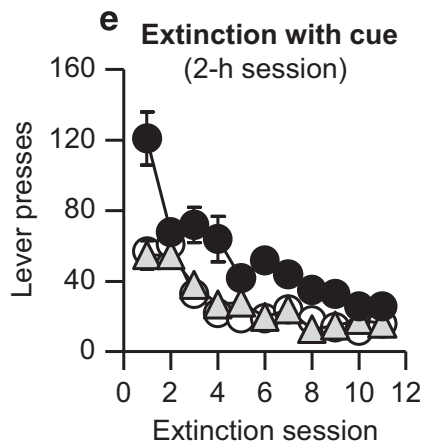

f Priming reinstatement

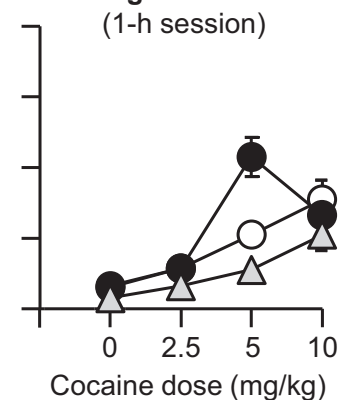

Wistar rats: homecage exposure

$\triangle$ Wistar rats: vapor exposure

P-rats: homecage exposure

Figure 5 Comparison of cocaine-taking and cocaine-seeking behaviors across experiments. (a) Acquisition of cocaine self-administration with ascending doses of cocaine ( $3 \mathrm{~d}$ per dose). (b) Within-session doseresponse curve after acquisition of cocaine self-administration. (c) Extinction responding without the cue over nine extinction sessions. (d) Cue-induced reinstatement of cocaine seeking. (e) Extinction responding with cue over I I extinction sessions. ( $f$ ) Cocaine priming-induced reinstatement. Data are presented as mean \pm SEM; comparison between Exp. I-3.

(session 1-9), showed a significant effect of Extinction session $\left(\mathrm{F}_{8,184}=8.0, p<0.01\right)$ but no effects of Pre-exposure condition or an interaction between the two factors ( $p$-values $>0.05)$.

Cue-induced reinstatement (right panel). The analysis of number of active lever presses showed a significant effect of Cue condition $\left(\mathrm{F}_{1,23}=13.6, p<0.01\right)$ but no effects of Pre-exposure condition or an interaction between the two factors ( $p$-values $>0.05)$. 
Extinction with cue and priming-induced reinstatement

Extinction with cue (left panel). (Figure 4, Exp. 3) The analysis of number of active lever presses showed a significant effect of Extinction session (session 1-11) $\left(\mathrm{F}_{10,}, 230=\right.$ 2.3, $p<0.05)$ but no effects of Pre-exposure condition or an interaction between the two factors ( $p$-values $>0.05)$.

Priming-induced reinstatement (right panel). The statistical analysis of number of active lever presses showed significant effects of Cocaine priming dose $\left(\mathrm{F}_{3,69}=6.8\right.$, $p<0.01$ ) but no effects of Pre-exposure condition or an interaction between the two factors ( $p$-values $>0.05)$.

Comparison of cocaine-taking and cocaine-seeking behaviors across experiments. (Figure 5) Finally, visual inspection of the data in Figures 2-4 indicate that independent of the alcohol pre-exposure conditions, the rats in Exp. 1-3 showed some differences in their cocaine-taking and cocaine-seeking behaviors in the different experimental phases. In particular, the rats with vapor exposure (Exp. 2) were slower to initiate cocaine self-administration and the $\mathrm{P}$ rats (Exp. 3) showed enhanced responding during the extinction and reinstatement tests (see Discussion). Note: we are confident that the rats in Exp. 2 have learned to lever press for cocaine, as indicated by the clear differences between active and inactive lever presses during acquisition (Supplementary Figure S1) and the observations of an orderly cocaine dose-response after training (Figure 2, Exp. 2).

\section{DISCUSSION}

We have used established rat models of alcohol drinking and dependence (Simms et al, 2008; Vendruscolo and Roberts, 2014), cocaine self-administration (Schuster and Thompson, 1969), and reinstatement of cocaine seeking (Shaham et al, 2003; Venniro et al, 2016) to determine whether different forms of alcohol exposure during the adolescence and young adult phase (Figure 1) will increase subsequent cocaine taking and seeking in Wistar or alcohol-preferring $\mathrm{P}$ rats. We found that prior drinking of moderate or higher amounts of $20 \%$ alcohol or exposure to intoxicating levels of alcohol (vapor chambers) had no effect on acquisition of cocaine self-administration, dose-response after acquisition, extinction responding, and cue- and cocaine-priming-induced reinstatement of cocaine seeking. Together, our data from established rat models suggest that alcohol exposure during late adolescence/young adulthood does not increase vulnerability to cocaine self-administration and relapse to cocaine seeking during adulthood.

\section{Methodological and Conceptual Considerations}

We provided converging data from the different addiction phases (initiation, maintenance, abstinence, relapse), as they are assessed in rat models, that alcohol pre-exposure does not promote cocaine taking and seeking. These data do not support the gateway hypothesis but as with any data from rodent models of drug addiction and relapse, the generality to the human condition should be made with caution (Epstein et al, 2006; Markou et al, 1993). One general issue is that as with most studies using animal addiction models
(Heilig et al, 2016), the rats in our study and other preclinical studies inspired by the gateway hypothesis (see Introduction) were socially isolated throughout the experiment (Exp. 1 and 3) or during the cocaine self-administration phase (Exp. 2). In contrast, in humans the initiation of binge drinking during late adolescence and early adulthood is largely driven by social factors (eg, peer pressure, college drinking parties) (Marzell et al, 2015).

Another issue is that we have used a limited access 2-h/day cocaine self-administration procedure for a relatively short time (12 days). Thus, a question for future research is whether prior alcohol exposure will increase vulnerability to cocaine self-administration in animal models that more closely mimic the human condition. These include the extended daily access escalation model (Ahmed, 2011), the unlimited daily access binge model (Bozarth and Wise, 1985; Tornatzky and Miczek, 2000), the DSM-IV-based model in which rats self-administer cocaine for several months (Deroche-Gamonet and Piazza, 2014; Piazza and DerocheGamonet, 2013), or cocaine self-administration models in which rats are given intermittent access to cocaine during extended daily training sessions, leading to binge-like drug intake (Roberts et al, 2007, 2013).

From an addiction perspective, another issue for future research is whether alcohol pre-exposure will increase cocaine taking and seeking in rat models of drug selfadministration and relapse in which cocaine selfadministration is suppressed by adverse consequences (eg, punishment or electric barrier) (Cooper et al, 2007; Pelloux et al, 2007) or in recent animal models of relapse after punishment-imposed or alternative reward choicebased voluntary abstinence (Caprioli et al, 2015; Krasnova et al, 2014; Marchant et al, 2013; Venniro et al, 2016).

Another issue to consider regarding the generality of the findings to the human condition is the homology between the alcohol pre-exposure developmental period in our study and age of onset of alcohol drinking in humans. In this regard, we started the alcohol exposure in the different experiments between PD 44-64, which corresponds to late adolescence and early adulthood developmental periods of the rat (McCutcheon and Marinelli, 2009; Spear, 2015). These developmental periods correspond to the time of onset of binge drinking in the majority of subjects in epidemiology studies (Davoren et al, 2016; Hingson and Zha, 2009), but do not capture the early- and mid-adolescence periods of humans. Thus, our results may not generalize to early developmental periods in which binge drinking is associated with increased risk to develop alcohol addiction in adulthood (Hingson and Zha, 2009). Another issue to consider regarding the generality of the findings to the human condition is that our rat model likely only captures some neurobiological aspects of the gateway hypothesis, and does not capture social, psychological, and legal aspects that can promote the transition from legal to illegal drugs that are beyond the scope of animal models of addiction.

Another issue that deserves some discussion is the finding that independent of the alcohol pre-exposure conditions, the rats in Exp. 1-3 showed some differences in their cocainetaking and cocaine-seeking behaviors in the different experimental phases. Specifically, the $\mathrm{P}$ rats in Exp. 2. showed enhanced responding during the extinction and reinstatement tests. These findings are consistent with a 
previous study (Le et al, 2006) that reported higher cocaine seeking in alcohol-naive $\mathrm{P}$ rats during extinction (with cue) and cocaine priming-induced reinstatement of drug seeking than in alcohol-naive non-preferring (NP) rats. In another study, Katner et al (2011) showed that alcohol-naive P rats will self-administer more cocaine into nucleus accumbens shell than Wistar rats, suggesting that $\mathrm{P}$ rats are more sensitive to some of the behavioral effects of cocaine and cocaine cues than Wistar rats. Together, the results from our study and the two studies mentioned above suggest that genetic factors that influence alcohol taking and seeking can also influence cocaine taking and seeking, and thus provide tentative support for the alternative hypothesis of a shared addiction vulnerability (Agrawal et al, 2004).

Another observation in our study was that the rats in Exp. 2 (vapor exposure) were slower to initiate cocaine selfadministration (Figure 5a). A possible explanation for this observation is that the rats in Exp. 2 were group-housed during the alcohol (or air) exposure for 7 weeks, whereas the rats in Exp. 1 and 3 were individually housed during this time period. Indeed, several previous studies have shown that group-housing during adolescence decreases cocaine selfadministration (Lu et al, 2003; Neisewander et al, 2012).

Finally, in reference to the general notion of the gateway hypothesis - that early legal drug use increases vulnerability to subsequent illegal drug use-we would like to point out that our results may only be relevant to alcohol and cocaine, but not to other combinations of legal and illegal drugs. We are particularly cautious with regard to the generality of our findings to heroin and prescription opioids, because there are many differences between the neurobiological mechanisms of opioids and psychostimulants, and the risk factors and environmental conditions that control addiction to these drug classes (Badiani, 2013; Badiani et al, 2011; Caprioli et al, 2009). In addition, there is evidence that prior exposure to nicotine during adolescence increases cocaine selfadministration (Reed and Izenwasser, 2016) and amphetamine self-administration and reinstatement (Cortright et al, 2012).

\section{Neurobiological Perspective}

It is well established that the rewarding effects of cocaine, as assessed in the drug self-administration procedure, are mediated by activation of the dopamine projection from the ventral tegmental area (VTA) to the nucleus accumbens (the mesolimbic dopamine system) (Roberts et al, 1977; Wise, 2004). There is also evidence that alcohol exposure increases dopamine cell firing in VTA and release of dopamine in nucleus accumbens (Di Chiara and Imperato, 1988; Gessa et al, 1985). In addition, pharmacological inhibition of dopamine transmission in VTA or nucleus accumbens decreases alcohol self-administration in rats (Hodge et al, 1993; Samson et al, 1993). These findings and the demonstration that rats will self-administer alcohol directly into the VTA (Gatto et al, 1994) have led to the popular notion that drug-induced activation of the mesolimbic dopamine system is critical for alcohol selfadministration and alcohol seeking (Engel and Jerlhag, 2014; Soderpalm and Ericson, 2013; Vengeliene et al, 2008).

From the perspective of common neurobiological mechanisms of alcohol and cocaine reward, the lack of effect of alcohol pre-exposure on cocaine-taking behavior in our study are unexpected. However, our findings are in agreement with results from several studies suggesting dissociable mechanisms of alcohol reward $v s$ cocaine reward. One example is that although the literature on the role of mesolimbic dopamine in cocaine self-administration is highly consistent (Pierce and Kumaresan, 2006; Wise, 1996), this is not the case for alcohol self-administration and intake in rat models. For example, Rassnick et al (1993) showed that 6-hydroxydopamine lesions of the mesolimbic dopamine system has no effect on alcohol self-administration, and Goodwin et al (1996) showed that systemic administration of the D2-family receptor antagonist pimozide has no effect on alcohol consumption; but see Files et al (1998) and Pfeffer and Samson (1988) for positive results with the D2-family receptor antagonists remoxipride and haloperidol.

Another example for dissociable mechanisms of alcohol vs cocaine taking and seeking is midbrain and striatal glial cell line-derived neurotrophic factor and brain-derived neurotrophic factor (Ghitza et al, 2010; Logrip et al, 2015; Ron and Barak, 2016). These growth factors provide trophic support to midbrain dopamine neurons (Hyman et al, 1991; Lin et al, 1993; Lindsay et al, 1994; Tomac et al, 1995), and have been shown to promote cocaine seeking (Graham et al, 2007; Grimm et al, 2003; Lu et al, 2004, 2009) but to suppress alcohol seeking (Barak et al, 2011; Carnicella et al, 2008, 2009; He et al, 2005).

A final example is the mu opioid receptor whose activation is critical for alcohol self-administration and intake (Herz, 1997; Sanchis-Segura et al, 2005; Trigo et al, 2010). In contrast, results from many pharmacological studies indicate that activation of this opioid receptor and more generally the endogenous opioid system has a minimal role in cocaine selfadministration (Badiani et al, 2011; Ettenberg et al, 1982; Mello and Negus, 1996).

\section{Conclusions}

Using multiple measures and procedures, we found no evidence that prior exposure to moderate, high, or intoxicating levels of alcohol increases cocaine self-administration and relapse to cocaine seeking in rat models. Our data do not support the notion that alcohol is a gateway drug for cocaine and suggest that the high co-morbidity seen in humans is likely due to time-independent shared addiction vulnerability, a notion supported by human epidemiological studies (Agrawal et al, 2004; Degenhardt et al, 2010; Tsuang et al, 1998; Vanyukov et al, 2012).

\section{FUNDING AND DISCLOSURE}

The research was supported by the Intramural Research Program of NIDA.

\section{ACKNOWLEDGMENTS}

We thank Daniele Caprioli, Marco Venniro, Felicia Surjono, and Michelle Zhang for help with surgeries and Lisa Thomas and Janaina Vendruscolo for technical assistance with the vapor model. 


\section{REFERENCES}

Agrawal A, Neale MC, Prescott CA, Kendler KS (2004). Cannabis and other illicit drugs: comorbid use and abuse/dependence in males and females. Behav Genet 34: 217-228.

Ahmed SH (2011). Escalation of drug use. Neuromethods 53: 267-292.

Badiani A (2013). Substance-specific environmental influences on drug use and drug preference in animals and humans. Curr Opin Neurobiol 23: 588-596.

Badiani A, Belin D, Epstein D, Calu D, Shaham Y (2011). Opiate versus psychostimulant addiction: the differences do matter. Nat Rev Neurosci 12: 685-700.

Barak S, Carnicella S, Yowell QV, Ron D (2011). Glial cell linederived neurotrophic factor reverses alcohol-induced allostasis of the mesolimbic dopaminergic system: implications for alcohol reward and seeking. J Neurosci 31: 9885-9894.

Bozarth MA, Wise RA (1985). Toxicity associated with long-term intravenous heroin and cocaine self- administration in the rat. J Am Med Assoc 254: 81-83.

Caprioli D, Celentano M, Dubla A, Lucantonio F, Nencini P, Badiani A (2009). Ambience and drug choice: cocaine- and heroin-taking as a function of environmental context in humans and rats. Biol Psychiatry 65: 893-899.

Caprioli D, Venniro M, Zeric T, Li X, Adhikary S, Madangopal R et al (2015). Effect of the novel positive allosteric modulator of metabotropic glutamate receptor 2 AZD8529 on incubation of methamphetamine craving after prolonged voluntary abstinence in a rat model. Biol Psychiatry 78: 463-473.

Carnicella S, Ahmadiantehrani S, Janak PH, Ron D (2009). GDNF is an endogenous negative regulator of ethanol-mediated reward and of ethanol consumption after a period of abstinence. Alcohol Clin Exp Res 33: 1012-1024.

Carnicella S, Kharazia V, Jeanblanc J, Janak PH, Ron D (2008). GDNF is a fast-acting potent inhibitor of alcohol consumption and relapse. Proc Natl Acad Sci USA 105: 8114-8119.

Cooper A, Barnea-Ygael N, Levy D, Shaham Y, Zangen A (2007). A conflict rat model of cue-induced relapse to cocaine seeking. Psychopharmacology 194: 117-125.

Cortright JJ, Sampedro GR, Neugebauer NM, Vezina P (2012). Previous exposure to nicotine enhances the incentive motivational effects of amphetamine via nicotine-associated contextual stimuli. Neuropsychopharmacology 37: 2277-2284.

Davoren MP, Demant J, Shiely F, Perry IJ (2016). Alcohol consumption among university students in Ireland and the United Kingdom from 2002 to 2014: a systematic review. BMC Public Health 16: 173.

de Wit H, Stewart J (1981). Reinstatement of cocaine-reinforced responding in the rat. Psychopharmacology (Berl) 75: 134-143.

Degenhardt L, Dierker L, Chiu WT, Medina-Mora ME, Neumark Y, Sampson N et al (2010). Evaluating the drug use 'gateway' theory using cross-national data: consistency and associations of the order of initiation of drug use among participants in the WHO World Mental Health Surveys. Drug Alcohol Depend 108: 84-97.

Deroche-Gamonet V, Piazza PV (2014). Psychobiology of cocaine addiction: Contribution of a multi-symptomatic animal model of loss of control. Neuropharmacology 76: 437-449.

Di Chiara G, Imperato A (1988). Drugs abused by humans preferentially increase synaptic dopamine transmission concentration in the mesolimbic system of freely moving rats. Proc Natl Acad Sci USA 85: 5274-5278.

Engel JA, Jerlhag E (2014). Alcohol: mechanisms along the mesolimbic dopamine system. Prog Brain Res 211: 201-233.

Epstein DH, Preston KL, Stewart J, Shaham Y (2006). Toward a model of drug relapse: an assessment of the validity of the reinstatement procedure. Psychopharmacology (Berl) 189: 1-16.
Ettenberg A, Pettit HO, Bloom FE, Koob GF (1982). Heroin and cocaine intravenous self-administration in rats: mediation by separate neural systems. Psychopharmacology (Berl) 78: 204-209.

Files FJ, Denning CE, Samson HH (1998). Effects of the atypical antipsychotic remoxipride on alcohol self-administration. Pharmacol Biochem Behav 59: 281-285.

Gatto GJ, McBride WJ, Murphy JM, Lumeng L, Li TK (1994). Ethanol self-infusion into the ventral tegmental area by alcoholpreferring rats. Alcohol 11: 557-564.

Gessa GL, Muntoni F, Collu M, Vargiu L, Mereu G (1985). Low doses of ethanol activate dopaminergic neurons in the ventral tegmental area. Brain Res 348: 201-203.

Ghitza UE, Zhai H, Wu P, Airavaara M, Shaham Y, Lu L (2010). Role of BDNF and GDNF in drug reward and relapse: a review. Neurosci Biobehav Rev 35: 157-171.

Goeders NE, Guerin GF (1994). Non-contingent electric footshock facilitates the acquisition of intravenous cocaine selfadministration in rats. Psychopharmacology (Berl) 114: 63-70.

Goodwin FL, Koechling UM, Smith BR, Amit Z (1996). Lack of effect of dopamine D2 blockade on ethanol intake in selected and unselected strains of rats. Alcohol 13: 273-279.

Graham DL, Edwards S, Bachtell RK, DiLeone RJ, Rios M, Self DW (2007). Dynamic BDNF activity in nucleus accumbens with cocaine use increases self-administration and relapse. Nat Neurosci 10: 1029-1037.

Grimm JW, Lu L, Hayashi T, Hope BT, Su TP, Shaham Y (2003). Time-dependent increases in brain-derived neurotrophic factor protein levels within the mesolimbic dopamine system after withdrawal from cocaine: implications for incubation of cocaine craving. J Neurosci 23: 742-747.

He DY, McGough NN, Ravindranathan A, Jeanblanc J, Logrip ML, Phamluong $\mathrm{K}$ et al (2005). Glial cell line-derived neurotrophic factor mediates the desirable actions of the anti-addiction drug ibogaine against alcohol consumption. J Neurosci 25: 619-628.

Heilig M, Epstein DH, Nader MA, Shaham Y (2016). Time to connect: bringing social context into addiction neuroscience. Nat Rev Neurosci 17: 592-599.

Herz A (1997). Endogenous opioid systems and alcohol addiction. Psychopharmacology 129: 99-111.

Hingson RW, Zha W (2009). Age of drinking onset, alcohol use disorders, frequent heavy drinking, and unintentionally injuring oneself and others after drinking. Pediatrics 123: 1477-1484.

Hodge CW, Haraguchi M, Erickson H, Samson HH (1993). Ventral tegmental microinjections of quinpirole decrease ethanol and sucrose-reinforced responding. Alcohol Clin Exp Res 17: 370-375.

Hutchison MA, Riley AL (2012). Ethanol exposure during either adolescence or adulthood alters the rewarding effects of cocaine in adult rats. Pharmacol Biochem Behav 101: 458-464.

Hyman C, Hofer M, Barde YA, Juhasz M, Yancopoulos GD, Squinto SP et al (1991). BDNF is a neurotrophic factor for dopaminergic neurons of the substantia nigra. Nature 350: $230-232$

Johnston LD, O’Malley PM, Miech RA, Bachman JG, Schulenberg JE (2014). Monitoring the Future National Survey Results on Drug Use, 1975-2013. Ann Arbor, MI: University of Michigan Institute for Social Research.

Kandel D (1975). Stages in adolescent involvement in drug use. Science 190: 912-914.

Kandel DB, Yamaguchi K, Chen K (1992). Stages of progression in drug involvement from adolescence to adulthood: further evidence for the gateway theory. J Stud Alcohol 53: 447-457.

Katner SN, Oster SM, Ding ZM, Deehan GA Jr, Toalston JE, Hauser SR et al (2011). Alcohol-preferring (P) rats are more sensitive than Wistar rats to the reinforcing effects of cocaine selfadministered directly into the nucleus accumbens shell. Pharmacol Biochem Behav 99: 688-695.

Kirby T, Barry AE (2012). Alcohol as a gateway drug: a study of US 12th graders. J Sch Health 82: 371-379. 
Krasnova IN, Marchant NJ, Ladenheim B, McCoy MT, Panlilio LV, Bossert JM et al (2014). Incubation of methamphetamine and palatable food craving after punishment-induced abstinence. Neuropsychopharmacology 39: 2008-2016.

Le AD, Li Z, Funk D, Shram M, Li TK, Shaham Y (2006). Increased vulnerability to nicotine self-administration and relapse in alcohol-naive offspring of rats selectively bred for high alcohol intake. J Neurosci 26: 1872-1879.

Le Pen G, Duterte-Boucher D, Daoust M, Costentin J (1998). Preexposure to alcohol does not sensitize to the rewarding effects of cocaine. Neuroreport 9: 2887-2891.

Lin LF, Doherty DH, Lile JD, Bektesh S, Collins F (1993). GDNF: a glial cell line-derived neurotrophic factor for midbrain dopaminergic neurons. Science 260: 1130-1132.

Lindsay RM, Wiegand SJ, Altar CA, DiStefano PS (1994). Neurotrophic factors: from molecule to man. Trends Neurosci 17: 182-190.

Logrip ML, Barak S, Warnault V, Ron D (2015). Corticostriatal BDNF and alcohol addiction. Brain Res 1628: 60-67.

Lu L, Dempsey J, Liu SY, Bossert JM, Shaham Y (2004). A single infusion of brain-derived neurotrophic factor into the ventral tegmental area induces long-lasting potentiation of cocaine seeking after withdrawal. J Neurosci 24: 1604-1611.

Lu L, Shepard JD, Hall FS, Shaham Y (2003). Effect of environmental stressors on opiate and psychostimulant reinforcement, reinstatement and discrimination in rats: a review. Neurosci Biobehav Rev 27: 457-491.

Lu L, Wang X, Wu P, Xu C, Zhao M, Morales M et al (2009). Role of ventral tegmental area glial cell line-derived neurotrophic factor in incubation of cocaine craving. Biol Psychiatry 66: 137-145.

Marchant NJ, Khuc TN, Pickens CL, Bonci A, Shaham Y (2013). Context-induced relapse to alcohol seeking after punishment in a rat model. Biol Psychiatry 73: 256-262.

Marinelli M, Piazza PV (2002). Interaction between glucocorticoid hormones, stress and psychostimulant drugs. Eur J Neurosci 16: 387-394.

Markou A, Weiss F, Gold LH, Caine SB, Schulteis G, Koob GF (1993). Animal models of drug craving. Psychopharmacology 112: 163-182.

Marzell M, Bavarian N, Paschall MJ, Mair C, Saltz RF (2015). Party characteristics, drinking settings, and college students' risk of intoxication: a multi-campus study. J Prim Prev 36: 247-258.

Mateos-Garcia A, Manzanedo C, Rodriguez-Arias M, Aguilar MA, Reig-Sanchis E, Navarro-Frances CI et al (2015). Sex differences in the long-lasting consequences of adolescent ethanol exposure for the rewarding effects of cocaine in mice. Psychopharmacology (Berl) 232: 2995-3007.

McCutcheon JE, Marinelli M (2009). Age matters. Eur J Neurosci 29: 997-1014.

Meil WM, See RE (1996). Conditioned cued recovery of responding following prolonged withdrawal from self-administered cocaine in rats: an animal model of relapse. Behav Pharmacol 7: 754-763.

Mello NK, Negus SS (1996). Preclinical evaluation of pharmacotherapies for treatment of cocaine and opioid abuse using drug self-administration procedures. Neuropsychopharmacology 14: 375-424.

Mierzejewski P, Rogowski A, Stefanski R, Goldberg S, Kostowski W, Bienkowski P (2003). Ethanol-reinforced behaviour predicts acquisition but not extinction of cocaine self-administration in the rat. Alcohol Alcohol 38: 543-549.

Molet J, Herve D, Thiebot MH, Hamon M, Lanfumey L (2013). Juvenile ethanol exposure increases rewarding properties of cocaine and morphine in adult DBA/2J mice. Eur Neuropsychopharmacol 23: 1816-1825.

Neisewander JL, Peartree NA, Pentkowski NS (2012). Emotional valence and context of social influences on drug abuse-related behavior in animal models of social stress and prosocial interaction. Psychopharmacology (Berl) 224: 33-56.
Pelloux Y, Everitt BJ, Dickinson A (2007). Compulsive drug seeking by rats under punishment: effects of drug taking history. Psychopharmacology 194: 127-137.

Pfeffer AO, Samson HH (1988). Haloperidol and apomorphine effects on ethanol reinforcement in free feeding rats. Pharmacol Biochem Behav 29: 343-350.

Philpot RM, Badanich KA, Kirstein CL (2003). Place conditioning: age-related changes in the rewarding and aversive effects of alcohol. Alcohol Clin Exp Res 27: 593-599.

Piazza PV, Deroche-Gamonet V (2013). A multistep general theory of transition to addiction. Psychopharmacology (Berl) 229: 387-413.

Piazza PV, Le Moal M (1998). The role of stress in drug selfadministration. Trends Pharmacol Sci 19: 67-74.

Pierce RC, Kumaresan V (2006). The mesolimbic dopamine system: the final common pathway for the reinforcing effect of drugs of abuse? Neurosci Biobehav Rev 30: 215-238.

Rassnick S, Stinus L, Koob GF (1993). The effects of 6hydroxydopamine lesions of the nucleus accumbens and the mesolimbic dopamine system on oral self-administration of ethanol in the rat. Brain Res 623: 16-24.

Reed SC, Izenwasser S (2016). Nicotine produces long-term increases in cocaine reinforcement in adolescent but not adult rats. Brain Res S0006-8993: 30535-2.

Roberts AJ, Heyser CJ, Cole M, Griffin P, Koob GF (2000). Excessive ethanol drinking following a history of dependence: animal model of allostasis. Neuropsychopharmacology 22: 581-594.

Roberts DC, Corcoran ME, Fibiger HC (1977). On the role of ascending catecholaminergic systems in intravenous selfadministration of cocaine. Pharmacol Biochem Behav 6: 615-620.

Roberts DC, Gabriele A, Zimmer BA (2013). Conflation of cocaine seeking and cocaine taking responses in IV self-administration experiments in rats: methodological and interpretational considerations. Neurosci Biobehav Rev 37: 2026-2036.

Roberts DC, Morgan D, Liu Y (2007). How to make a rat addicted to cocaine. Prog Neuropsychopharmacol Biol Psychiatry 31: 1614-1624.

Ron D, Barak S (2016). Molecular mechanisms underlying alcoholdrinking behaviours. Nat Rev Neurosci 17: 576-591.

Samson HH, Hodge CW, Tolliver GA, Haraguchi M (1993). Effect of dopamine agonists and antagonists on ethanol-reinforced behavior: the involvement of the nucleus accumbens. Brain Res Bull 30: 133-141.

Sanchis-Segura C, Grisel JE, Olive MF, Ghozland S, Koob GF, Roberts AJ et al (2005). Role of the endogenous opioid system on the neuropsychopharmacological effects of ethanol: new insights about an old question. Alcohol Clin Exp Res 29: 1522-1527.

Sarnyai Z, Shaham Y, Heinrichs SC (2001). The role of corticotropin-releasing factor in drug addiction. Pharmacol Rev 53: 209-244.

Schuster CR, Thompson T (1969). Self administration of and behavioral dependence on drugs. Annu Rev Pharmacol 9: 483-502.

Shaham Y, Shalev U, Lu L, De Wit H, Stewart J (2003). The reinstatement model of drug relapse: history, methodology and major findings. Psychopharmacology 168: 3-20.

Shalev U, Grimm JW, Shaham Y (2002). Neurobiology of relapse to heroin and cocaine seeking: a review. Pharmacol Rev 54: 1-42.

Simms JA, Steensland P, Medina B, Abernathy KE, Chandler LJ, Wise $\mathrm{R}$ et al (2008). Intermittent access to $20 \%$ ethanol induces high ethanol consumption in Long-Evans and Wistar rats. Alcohol Clin Exp Res 32: 1816-1823.

Soderpalm B, Ericson M (2013). Neurocircuitry involved in the development of alcohol addiction: the dopamine system and its access points. Curr Top Behav Neurosci 13: 127-161. 
Spear LP (2015). Adolescent alcohol exposure: Are there separable vulnerable periods within adolescence? Physiol Behav 148: $122-130$.

Stewart J, Woodside BC, Shaham Y (1996). Changes in ovarian hormones do not affect the initiation of intravenous selfadministration of heroin in the female rat. Psychobiology 24: 154-159.

Tomac A, Lindqvist E, Lin LF, Ogren SO, Young D, Hoffer BJ et al (1995). Protection and repair of the nigrostriatal dopaminergic system by GDNF in vivo. Nature 373: 335-339.

Tornatzky W, Miczek KA (2000). Cocaine self-administration 'binges': transition from behavioral and autonomic regulation toward homeostatic dysregulation in rats. Psychopharmacology (Berl) 148: 289-298.

Trigo JM, Martin-Garcia E, Berrendero F, Robledo P, Maldonado R (2010). The endogenous opioid system: a common substrate in drug addiction. Drug Alcohol Depend 108: 183-194.

Tsuang MT, Lyons MJ, Meyer JM, Doyle T, Eisen SA, Goldberg J et al (1998). Co-occurrence of abuse of different drugs in men: the role of drug-specific and shared vulnerabilities. Arch Gen Psychiatry 55: 967-972.

Vanyukov MM, Tarter RE, Kirillova GP, Kirisci L, Reynolds MD, Kreek MJ et al (2012). Common liability to addiction and 'gateway hypothesis': theoretical, empirical and evolutionary perspective. Drug Alcohol Depend 123: S3-17.

Vendruscolo LF, Roberts AJ (2014). Operant alcohol selfadministration in dependent rats: focus on the vapor model. Alcohol 48: 277-286.

Vengeliene V, Bilbao A, Molander A, Spanagel R (2008). Neuropharmacology of alcohol addiction. $\mathrm{Br} J$ Pharmacol 154: 299-315.

Venniro M, Caprioli D, Shaham Y (2016). Animal models of drug relapse and craving: from drug priming-induced reinstatement to incubation of craving after voluntary abstinence. Prog Brain Res, 224: 25-52.

Wise RA (1973). Voluntary ethanol intake in rats following exposure to ethanol on various schedules. Psychopharmacologia 29: 203-210.

Wise RA (1996). Neurobiology of addiction. Curr Opin Neurobiol 6: 243-251.

Wise RA (2004). Dopamine, learning and motivation. Nat Rev Neurosci 5: 483-494.

Yokel RA (1987). Intravenous self-administration: response rates, the effects of pharmacological challenges, and drug preference. In: Bozarth MA (ed). Methods of Assessing the Reinforcing Properties of Abused Drugs. Springer-Verlag: New York, pp 1-34.

Supplementary Information accompanies the paper on the Neuropsychopharmacology website (http://www.nature.com/npp) 